\title{
Optimal ratios of essential amino acids stimulate $\beta$-casein synthesis via activation of the mammalian target of rapamycin signaling pathway in MAC-T cells and bovine mammary tissue explants
}

\author{
S. S. Li, ${ }^{*}$ J. J. Loor, $\dagger^{1}$ H. Y. Liu, ${ }^{*}$ L. Liu, ${ }^{*}$ A. Hosseini, $†$ W. S. Zhao, $†$ and J. X. Liu*1 \\ *Institute of Dairy Science, College of Animal Sciences, MoE Key Laboratory of Molecular Animal Nutrition, Zhejiang University, \\ Hangzhou 310058, P. R. China \\ †Mammalian NutriPhysioGenomics, Department of Animal Sciences and Division of Nutritional Sciences, University of Illinois, Urbana 61801
}

\begin{abstract}
Amino acids are the building blocks of proteins and serve as key molecular components upstream of the signaling pathways that regulate protein synthesis. The objective of this study was to systematically investigate the effect of essential AA ratios on milk protein synthesis in vitro and to elucidate some of the underlying mechanisms. Triplicate cultures of MAC-T cells and bovine mammary tissue explants (MTE) were incubated with the optimal AA ratio (OPAA; Lys:Met, 2.9:1; Thr:Phe, 1.05:1; Lys:Thr, 1.8:1; Lys:His, 2.38:1; and Lys:Val, 1.23:1) in the presence of rapamycin (control), OPAA, a Lys:Thr ratio of 2.1:1, a Lys:Thr ratio of $1.3: 1$, a Lys:His ratio of $3.05: 1$, or a Lys:Val ratio of $1.62: 1$ for $12 \mathrm{~h}$; the other AA concentrations were equal to OPAA. In some experiments, the cells were cultured with OPAA with or without rapamycin $(100 \mathrm{ng} / \mathrm{mL})$ or with mammalian target of rapamycin (mTOR) small interference RNA, and the MTE were exposed to OPAA with rapamycin for $\beta$-casein expression. Among the treatments, the expression of $\beta$-casein was greatest in the MTE cultured with OPAA. In MAC-T cells, the OPAA upregulated the mRNA expression of $S L C 1 A 5$ and $S L C 7 A 5$ but downregulated the expression of IRS1, AKT3, EEF1A1, and EEF2 compared with the control. The OPAA had no effect on the mTOR phosphorylation status but increased the phosphorylation of S6K1 and RPS6. When the MTE were treated with rapamycin in the presence of OPAA, the expression of $\beta$-casein was markedly decreased. The phosphorylation of RPS6 and 4EBP1 also was reduced in MAC-T cells. A similar negative effect on the expression of RPS6KB1 and EIF4EBP1 was detected when the cells were cultured with either rapamycin or
\end{abstract}

Received February 2, 2017.

Accepted April 17, 2017.

${ }^{1}$ Corresponding authors: liujx@zju.edu.cn and jloor@illinois.edu
mTOR small interference RNA. The optimal AA ratio stimulated $\beta$-casein expression partly by enhancing the transport of AA into the cells, cross-talk with insulin signaling and a subsequent enhancement of mTOR signaling, or translation elongation in both MAC-T cells and bovine MTE.

Key words: mammalian target of rapamycin, signaling protein, milk protein synthesis, MAC-T cell, bovine mammary tissue explant

\section{INTRODUCTION}

Balancing the profiles of EAA can improve the utilization efficiency of dietary nitrogen and enhance bovine milk protein synthesis (Haque et al., 2015). Because milk protein is a nutrient that strongly supports human health, several studies have focused on the positive effect of AA on milk protein synthesis in mammary epithelial cells (MEC). Threonine and Met were the 2 AA first determined to be limiting for milk protein synthesis in bovine MEC (Clark et al., 1978). Subsequently, effects of individual EAA on the $\beta$-CN content and mRNA expression, fractional protein synthesis rate, and downstream signaling in bovine MEC have been reported (Appuhamy et al., 2012; Wang et al., 2014; Gao et al., 2015).

Research with dairy cows and bovine MEC has revealed an important role of the proper ratio of Lys to Met in the control of milk protein synthesis, including the stimulation of milk production (Wang et al., 2010; Nan et al., 2014). In dairy cows, a profile of EAA for milk synthesis or intestinally absorbed EAA has been recommended by NRC (2001) and Rulquin et al. (2007). Studies on EAA requirements revealed that balancing for His or Val in diets could increase milk protein yield (Lee et al., 2012; Haque et al., 2013). However, aside from studies on the ratio of Lys to Met, there is limited information on the milk protein synthesis response to alterations in the supply of Thr, His, and Val relative to that of Lys in bovine MEC. Therefore, studies focused 
on the optimal ratio of these AA could help better explain the mechanisms by which milk protein synthesis is regulated in response to the balance of EAA. Because mammalian target of rapamycin (mTOR) is a nutrient-sensing kinase with a well-characterized signaling pathway that is regulated by AA (Jewell et al., 2013; Kim et al., 2013), it is likely that a relationship exists between the EAA ratios and the mTOR signaling pathway.

In nonruminants, mTOR is recognized as a critical regulator of cellular protein synthesis that is activated when the cellular levels of key nutrients including AA, glucose, and oxygen are sufficient (Dibble and Manning, 2013). Once activated, mTOR complex 1 (mTORC1) is phosphorylated and activates the ribosomal protein S6 kinase 1 (S6K1) to phosphorylate ribosomal protein S6 (RPS6), which is a component of the 40S ribosomal subunit. Meanwhile, mTORC1 phosphorylates eukaryotic initiation factor (eIF) 4E binding protein 1 (4EBP1), which causes the release of $4 \mathrm{EBP} 1$ from the key initiation factor (eIF4E) and promotes the initiation of translation (Shimobayashi and Hall, 2014).

Translational initiation is mediated by the alpha subunit of eukaryotic translation initiation factor 2 (eIF2 $\alpha$ ), which induces the binding of the initiator methionyl-tRNA to the 40S ribosomal subunits (Proud, 2007). Subsequently, elongation factor 2 (eEF2) mediates the translocation step during elongation (Kaul et al., 2011). Recent evidence has indicated that in murine MEC, the total AA concentration governs global protein and $\beta$-lactoglobulin synthesis at the translational level (Moshel et al., 2006). In monogastric cell lines and tissues, the stimulation of protein synthesis through mTOR signaling is activated by individual AA, in particular Leu (Areta et al., 2014). However, it is unclear whether the mTOR signaling pathway can be activated directly by changes in the EAA ratios in bovine MEC and, if so, what the underlying mechanisms might be.

Our general hypothesis was that the ratios of EAA could potentially affect the milk protein content by regulating cellular signals in bovine mammary cells at both transcriptional and posttranslational levels at least in part via mTOR. Given that the expression of the gene networks that drive protein synthesis in bovine mammary glands during the lactation cycle are associated with AA (Bionaz and Loor, 2011), it is important to determine changes at the transcription level for genes that encode the AA and glucose transporters, insulin signaling, and Janus kinase 2-signal transducer and activator of transcription 5 (JAK2-STAT5). Therefore, the objective of this study was to use a systematic approach to investigate the effects of the ratios of Lys to Thr, His, and Val on milk protein synthesis in vitro.
The data from published studies with dairy cows were used to develop an optimal EAA ratio (OPAA) that could enhance milk protein content (NRC, 2001; Rulquin et al., 2007; Zhou et al., 2015).

\section{MATERIALS AND METHODS}

\section{Ethics Statement}

The care and handling of the dairy cows from which the mammary tissues were obtained were approved by the Institutional Animal Care and Use Committee at Zhejiang University of China.

\section{Cells and Tissue Culture}

All cell culture work was performed using an immortalized bovine mammary epithelial cell line, MAC-T, and mammary tissue explants (MTE) from lactating cows. The MAC-T cells were cultured on 6 -well plates $\left(20,000\right.$ cells $\left./ \mathrm{cm}^{2}\right)$ at $37^{\circ} \mathrm{C}$ in $5 \% \mathrm{CO}_{2}$. Before exposure to the treatments, the cells were grown to approximately $90 \%$ confluence as described by Kadegowda et al. (2009). Mammary tissue preparation and explants culture were performed as previously reported (Yang et al., 2015). Briefly, 3 multiparous, lactating, mastitisfree Holstein cows were obtained from Jiashan Dayang Animal Industries (Jiaxing, China), and the mammary tissues were harvested at the time of slaughter in a commercial facility. The mammary tissues were excised from the upper portion of the rear quarters. The MTE (100 mg) were prepared within $2 \mathrm{~h}$ of slaughter and placed in 6 -well plates. Each well contained $2.5 \mathrm{~mL}$ of growth medium that included insulin $(5 \mathrm{mg} / \mathrm{L})$, hydrocortisone $(1 \mathrm{mg} / \mathrm{L})$, prolactin $(5 \mathrm{mg} / \mathrm{L}), 1 \%$ glutamine, and $10 \%$ fetal bovine serum in complete Dulbecco's modified Eagle's medium (DMEM)/F12 (Gibco, Invitrogen, Carlsbad, CA). The MTE were cultured in the growth medium for $72 \mathrm{~h}$ before applying the treatments.

\section{Treatments and Experimental Design}

To determine the effect of the EAA ratios on $\beta$-CN expression, the MTE in 6-well plates were serum starved overnight and cultured for $12 \mathrm{~h}$ in serum-free media containing the treatments. All treatment media were prepared as lactogenic media as described by Kadegowda et al. (2009) except that high-glucose DMEM devoid of EAA (custom made from Gibco, Invitrogen) was used instead of minimum essential medium with Earle's balanced salts. Six treatments were designed as reported previously (Supplementary Table 
S1, https://doi.org/10.3168/jds.2017-12681; Li et al., 2016). The data from published studies with dairy cows were used to develop an OPAA that could enhance milk protein content. Briefly, the treatments were (1) OPAA (Lys:Met, 2.9:1; Thr:Phe, 1.05:1; Lys:Thr, 1.8:1; Lys:His, 2.38:1; and Lys:Val, 1.23:1) in the presence of rapamycin (control), (2) OPAA, (3) Lys:Thr ratio of 2.1 (LT2.1), (4) Lys:Thr ratio of 1.3 (LT1.3); (4) Lys:His ratio of 3.05 (LH3.0), and Lys:Val ratio at 1.62 (LV1.6). All other AA in LT2.1, LT1.3, LH3.0, and LV1.6 had equal concentrations to OPAA in the high-glucose DMEM. The media were prepared from the custom high-glucose DMEM by supplementation with the individual EAA (L-isomers), which were purchased from Sigma-Aldrich (St. Louis, MO). After 12 $\mathrm{h}$, the MTE were scraped into 1.5-mL tubes and stored at $-80^{\circ} \mathrm{C}$. Before use, the MTE were homogenized and then lysed with $200 \mu \mathrm{L}$ of radio immunoprecipitation assay lysis buffer (Beyotime, Haimen, Jiangsu, China) and centrifuged at $12,000 \times \mathrm{g}$ for $15 \mathrm{~min}$ at $4^{\circ} \mathrm{C}$. The supernatant was then stored at $-80^{\circ} \mathrm{C}$ until Western blot analysis.

In general, the experimental design and treatments for the MAC-T cells were the same as those for the tissue experiment with some modifications. After $12 \mathrm{~h}$ of treatment, the cells were harvested by scraping in $1 \mathrm{~mL}$ of Qiazol reagent (Invitrogen) and stored at $-80^{\circ} \mathrm{C}$ for the RNA analysis. For the protein analysis, the culture plates were placed on ice and cells were scraped into an ice-cold radio immunoprecipitation assay lysis buffer containing $1 \%$ of a protease and phosphatase inhibitor (Sangon Biotech, Shanghai, China). The cell lysates were centrifuged at $12,000 \times g$ for $15 \mathrm{~min}$ at $4^{\circ} \mathrm{C}$, and the supernatant was stored at $-80^{\circ} \mathrm{C}$ until Western blot analysis. The cell lysates from 3 wells were combined. The experiment was repeated 3 times on 3 different days.

To test the effects of OPAA and rapamycin on $\beta$-CN expression, the MTE were treated with OPAA in the absence or presence of rapamycin $(100 \mathrm{ng} / \mathrm{mL})$ for 12 $\mathrm{h}$. The $\beta$-CN expression was determined using Western blotting.

To test the effects of OPAA and rapamycin on cell signaling, the MAC-T cells were treated for $12 \mathrm{~h}$ as described earlier. The gene expression and abundance of mTOR, S6K1, and 4EBP1 were measured by realtime PCR and Western blotting.

To test the effect of OPAA and RNA interferencemediated silencing of mTOR, the MAC-T cells were treated for $12 \mathrm{~h}$ (1) without OPAA + negative control, (2) without OPAA + mTOR small interference (si) RNA, (3) with OPAA + negative control, or (4) with OPAA + mTOR siRNA. The gene expression of mTOR, S6K1, and 4EBP1 was measured by real-time PCR.

\section{RNA Extraction and Real-Time PCR Analysis}

To evaluate the effect of the EAA ratio in the cell signaling experiment, the total RNA was isolated from the cells using the RNeasy Mini Kit (Qiagen, Valencia, CA). The RNA concentrations were determined using a Nano Drop ND-1000 spectrophotometer (NanoDrop Technologies, Wilmington, DE). The RNA integrity was assessed using an Agilent 2100 Bioanalyzer (Agilent Technologies, Santa Clara, CA). The RNA integrity number factor was above 7.5. Before reverse transcription, a portion of the RNA was diluted to $100 \mathrm{ng} / \mu \mathrm{L}$ using RNase-free water.

The cDNA was synthesized using $100 \mathrm{ng}$ of RNA as reported previously ( $\mathrm{Li}$ et al., 2016). The quantitative PCR was performed using $4 \mu \mathrm{L}$ of diluted cDNA combined with $6 \mu \mathrm{L}$ of a mixture comprising $5 \mu \mathrm{L}$ of $1 \times$ SYBR Green Master Mix (Quanta, Gaithersburg, MD), $0.4 \mu \mathrm{L}$ each of $10 \mu \mathrm{M}$ forward and reverse primers, and $0.2 \mu \mathrm{L}$ of RNase-free water. The genes GAPDH, UXT, and $R P S 9$ were used as the reference genes; the primer sequence for the target genes is listed in Supplementary Table S2 (https://doi.org/10.3168/jds.2017-12681). The quantitative PCR reactions were performed in an ABI Prism 7900HT SDS instrument (Applied Biosystems, Foster City, CA) using the following program: $95^{\circ} \mathrm{C}$ for 5 min followed by 40 cycles of $95^{\circ} \mathrm{C}$ for $1 \mathrm{~s}$ and $60^{\circ} \mathrm{C}$ for $30 \mathrm{~s}$. The presence of a single PCR product was verified using a dissociation protocol: $95^{\circ} \mathrm{C}$ for $15 \mathrm{~s}, 65^{\circ} \mathrm{C}$ for $15 \mathrm{~s}$, and $95^{\circ} \mathrm{C}$ for $15 \mathrm{~s}$. The data were analyzed using the standard curve with $7900 \mathrm{HT}$ Sequence Detection Systems software (version 2.4; Applied Biosystems). The methods used for the primer design and validation were as described by Bionaz and Loor (2011).

To examine the effect of OPAA and RNA interference-mediated inhibition of mTOR, the total RNA was isolated using the method described earlier. Subsequently, $1 \mu \mathrm{g}$ of total RNA from each cell sample was reversed transcribed using a PrimeScript RT reagent kit (Takara Bio Inc., Dalian, China). Then, the gene expression was determined by real-time PCR (Prism 7500, Applied Biosystems). The PCR was performed with SYBR Premix Ex Taq II (Takara Bio Inc.) using the following conditions: 1 cycle of $30 \mathrm{~s}$ at $95^{\circ} \mathrm{C}$ followed by 40 cycles of $5 \mathrm{~s}$ at $95^{\circ} \mathrm{C}$ and then $60^{\circ} \mathrm{C}$ for $34 \mathrm{~s}$. The data were normalized using the geometric mean of the responses of the internal controls, GAPDH, UXT, and RPS9. 


\section{Western Blotting}

Aliquots from the cell $(20 \mu \mathrm{g})$ and $\mathrm{MTE}(40 \mu \mathrm{g})$ lysates were subjected to Western blot analysis as previously described ( $\mathrm{Li}$ et al., 2015) with modifications. Briefly, the proteins were separated using SDS-PAGE and transferred to a polyvinylidene fluoride membrane (Millipore, Billerica, MA). After blocking with 3\% swine serum, the membrane was incubated with primary antibodies (all from Cell Signaling Technology, Danvers, MA) that recognized the phosphorylated forms of mTOR (Ser2448, cat. no. 2971), S6K1 (Thr389, cat. no. 9205), RPS6 (Ser235/236, cat. no. 2211), 4EBP1 (Thr37/46, cat. no. 9459), eIF2 $\alpha$ (Ser51, cat. no. 3597), and eEF2 (Thr56, cat. no. 2331) as well as with antibodies that recognized the total forms of mTOR (cat. no. 2972), S6K1 (cat. no. 9202), RPS6 (cat. no. 2217), 4EBP1 (cat. no. 9452), eIF2 $\alpha$ (cat. no. 2103), and eEF2 (cat. no. 2332). In addition, $\beta$-CN (BPI, Beijing, China) and $\beta$-actin (Boster, Wuhan, China) were analyzed. The signals were visualized with a BeyoECL Plus chemiluminescence system (Beyotime, Jiangsu, China) according to the manufacturer's protocol. Images of the membrane were captured using a Clinx Chemiscope 3400 Mini (Clinx Science Instruments, Shanghai, China). The relative quantity of each protein was defined according to the gray scale using Quantity One software (version 4.6.2; Bio-Rad, Berkeley, CA). The phosphorylation state was calculated as the ratio of the relative intensity of the phosphorylated form to the total protein.

\section{Transient Transfection and mTOR siRNA}

Three candidate siRNA that targeted mTOR and a noncoding scrambled sequence (negative control; Supplementary Table S3, https://doi.org/10.3168/ jds.2017-12681) were synthesized by Shanghai GenePharma Co. (Shanghai, China). The efficiency of the target silencing was determined using real-time PCR analysis in MAC-T cells $24 \mathrm{~h}$ after the siRNA transfection. The siRNA-3 sequence was selected for the subsequent assays because of its high effectiveness (77\% silencing efficiency; Supplementary Figure S1, https://doi.org/10.3168/jds.2017-12681). The MAC-T cells were transfected with either the mTOR siRNA or the negative control using the Lipofectamine 2000 reagent (Invitrogen, Carlsbad, CA) according to the manufacturer's protocol. Briefly, each siRNA (80 nM) was added to MAC-T cells in Opti-MEM reduced serum medium (Invitrogen), and the cultures were incubated for $6 \mathrm{~h}$. After removing the Opti-MEM medium, the cells were serum starved by adding the lactogenic medium to the wells for $9 \mathrm{~h}$, and the cells were subsequently used for testing the effect of OPAA and RNA interference-mediated silencing of mTOR.

\section{Gene Network Analysis}

The gene network analysis was conducted using the Ingenuity Pathway Analysis system (http://www.ingenuity.com). The interactions among the genes were analyzed according to the results from this study and the known relationships from the published papers on human, mouse, and rat genes and proteins.

\section{Statistical Analysis}

The data were evaluated using the MIXED procedure of SAS (version 9.1; SAS Institute Inc., Cary, $\mathrm{NC}$ ). Analysis of variance and Duncan's multiple range tests were used to determine the effects of OPAA and rapamycin or mTOR siRNA on the $\beta$-CN synthesis and cell signaling. Statistical significance was considered at $P \leq 0.05$.

\section{RESULTS}

\section{Effect of EAA Ratios on $\beta$-CN Expression and the mRNA Abundance of AA and Glucose Transporters, Signaling, and Translation Elongation Factors in the MTE or MAC-T Cells}

As shown in Figure 1, OPAA resulted in greater expression of $\beta-\mathrm{CN}(P<0.05)$ than the control, LT2.1, LH3.0, and LV1.6, but no differences were detected among the control, LT1.3, LT2.1, LH3.0, and LV1.6 $(P=0.07)$. Figure 2 shows the levels of expression of various genes that are involved in AA (Figure 2A) and glucose transport (Figure 2B), JAK2-STAT5 (Figure $2 \mathrm{C}$ ) and insulin (Figure 2D) signaling components, and translation elongation (Figure 2E). Compared with the control, the OPAA treatment upregulated $(P<0.01)$ the expression of solute carrier family 1 (neutral AA transporter) member $5(\boldsymbol{S L C 1} \boldsymbol{A 5})$ and solute carrier family 7 (cationic AA transporter, y+ system) member 5 (SLC7A5) but downregulated $(P<0.01)$ the expression of insulin receptor substrate 1 (IRS1), v-akt murine thymoma viral oncogene homolog 3 (AKT3), eukaryotic translation elongation factor $1 \alpha$ 1 (EEF1 A1), and EEF2. Furthermore, compared with OPAA, LT2.1 induced greater expression $(P<0.05)$ of $S L C 7 A 5$, solute carrier family 3 (activators of dibasic and neutral AA transporter) member 2 (SLC3A2), solute carrier family 2 (facilitated glucose transporter) member 8 ( $\boldsymbol{S} \boldsymbol{L} \boldsymbol{C} \mathbf{2} \boldsymbol{A} \boldsymbol{8})$, and signal transducer and acti- 
vator of transcription $5 \mathrm{~A}(\boldsymbol{S T A T 5 B})$ as well as LT1.3 $(P<0.05)$, LH3.0 $(P<0.05)$, and LV1.6 $(P<0.05)$. Treatment with LT1.3 $(P<0.05)$ and LH3.0 $(P<0.05)$ led to greater mRNA expression of $S L C 1 A 5$, glucose transporter solute carrier family 2 (facilitated glucose transporter) member 1 (SLC2A1), and IRS1. Treatment with LV1.6 $(P<0.01)$ resulted in greater expression of solute carrier family 36 (proton/AA symporter) member 1 (SLC36A1), SLC2A1, EEF1A1, and EEF2.

\section{Effect of EAA Ratios on mRNA Expression and Phosphorylation of $m$ TOR Signaling in MAC-T Cells}

Relative to the control, OPAA upregulated the mRNA expression of ribosomal protein $\mathrm{S} 6$ kinase $\beta-1(\boldsymbol{R} \boldsymbol{P}$ S6 KB1; $P<0.01$ ) and downregulated the expression of tuberous sclerosis 2 ( $\boldsymbol{T S C 2} ; P<0.01$; Figure $3 \mathrm{~A})$. The mRNA expression of MTOR, RPS6KB1, TSC1, and TSC2 was greater with LV1.6 $(P<0.05)$, but this condition caused a decrease in the expression of EIF $4 E$ $(P<0.01)$ compared with OPAA. Compared with OPAA, treatment with LT1.3 increased $(P<0.05)$ the
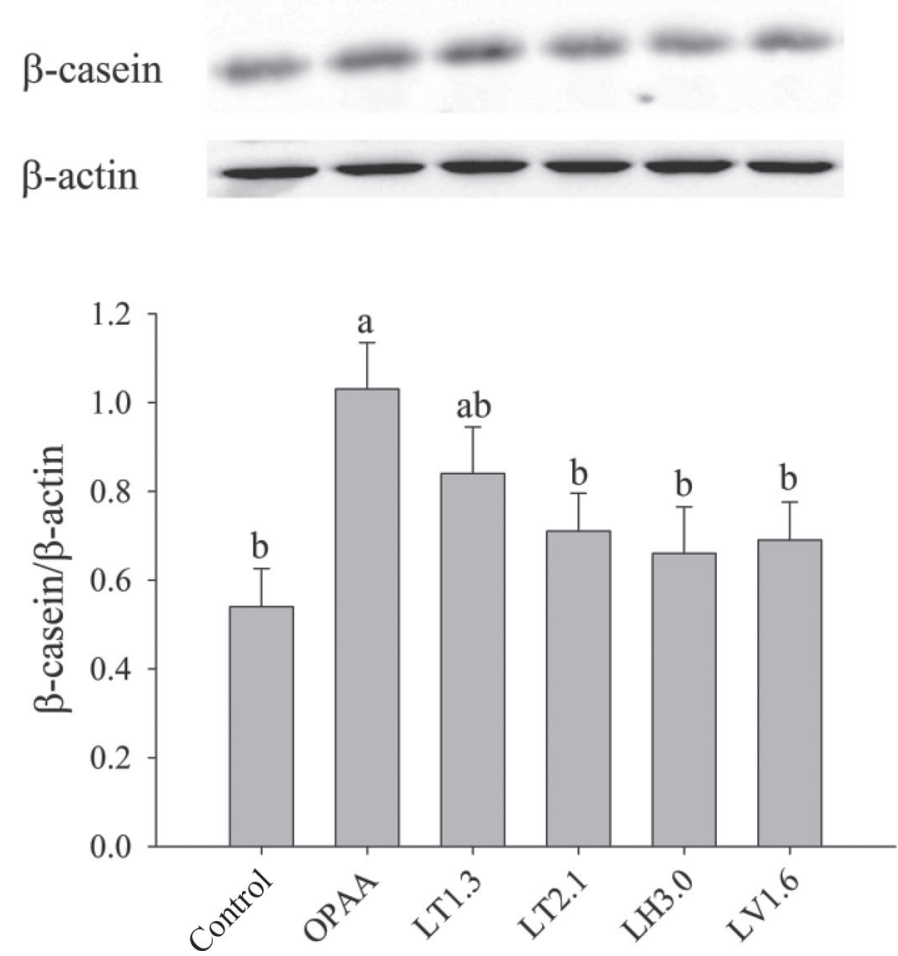

Figure 1. Relative protein expression of $\beta$ - $\mathrm{CN}$ in bovine mammary explants cultured with various ratios of the EAA. The values shown are the means \pm SEM ( $\mathrm{n}=3$ per group). Values without a common letter differ $(P<0.05)$. Control $=$ optimal AA with rapamycin; OPAA = optimal AA; LT1.3 = Lys:Thr ratio of 1.3; LT2.1 = Lys:Thr ratio of 2.1; LH3.0 = Lys:His ratio of 3.05; LV1.6 = Lys:Val ratio of 1.62. expression of Ras homolog enriched in brain $(\boldsymbol{R H} \boldsymbol{E} \boldsymbol{B})$ and TSC2, whereas LT2.1 $(P<0.05)$ or LH3.0 $(P<$ $0.05)$ increased the mRNA expression of RPS6KB1 and $T S C 1$. The potential regulatory networks of genes related to milk protein synthesis and the overall response to the treatments are summarized in Figure 4.

Compared with the control, treatment with OPAA had no effect on the phosphorylation state of mTOR $(P=0.10$; Figure 3B), whereas OPAA increased the phosphorylation of S6K1 $(P<0.01$; Figure $3 \mathrm{C})$ and RPS6 $(P<0.01$; Figure 3D). In addition, compared with OPAA, treatment with LT2.1, LH3.0, or LV1.6 decreased the phosphorylation of S6K1 $(P<0.01$; Figure $3 \mathrm{C}$ ). Furthermore, treatment with LH3.0 and LV1.6 decreased the phosphorylation of 4EBP1 $(P<0.05$; Figure $3 \mathrm{E})$, whereas it increased the phosphorylation of eEF2 $(P<0.01)$ compared with OPAA (Figure $3 \mathrm{G}$ ). There were no differences among the treatments for the phosphorylation of eIF $2 \alpha(P=0.56$; Figure $3 \mathrm{~F})$.

\section{Effect of OPAA Ratios and mTOR Inhibition on the Expression of $\beta-C N$ and $m T O R$ Signaling in MTE or MAC-T Cells}

On the basis of the high expression of $\beta-\mathrm{CN}$ that was induced by OPAA, we investigated whether mTOR could mediate the OPAA-induced stimulation of $\beta-\mathrm{CN}$ expression. When rapamycin was added, the increase of $\beta$-CN expression in the presence of OPAA was reduced by $56 \%(P<0.05$; Figure 5$)$. Rapamycin itself significantly inhibited the $\beta$-CN expression regardless of the presence of OPAA $(P<0.05)$.

Rapamycin markedly decreased the mRNA expression (by 54 or $32 \%$ with or without OPAA, respectively; $P<0.05)$ and the phosphorylation of mTOR (by 74 and $56 \%$ with or without OPAA, respectively; $P<0.05$; Figure $6 \mathrm{~A}$ and $6 \mathrm{~B})$. Furthermore, the mTOR siRNA decreased the expression of the mTOR mRNA (by 69 and $62 \%$ with or without OPAA, respectively; $P<0.05$; Figure 6C). Importantly, mTOR inhibition by rapamycin significantly decreased $(P<0.05)$ the mRNA expression of RPS6KB1 and EIF4EBP1 (Figure $6 \mathrm{~A}$ ) and the phosphorylation of RPS6 and 4EBP1 (Figure 6B). Similarly, following transfection with the mTOR siRNA, the mRNA expression of RPS6KB1 and EIF 4EBP1 was markedly decreased $(P<0.05$; Figure $6 \mathrm{C})$.

\section{DISCUSSION}

The availability of AA to the mammary gland is the main limiting factor for milk protein synthesis (Bionaz and Loor, 2011), with Lys and Met being the 2 most limiting AA in the bovine mammary glands ( $\mathrm{Lu}$ et 


\section{(A) Amino acid transporters}

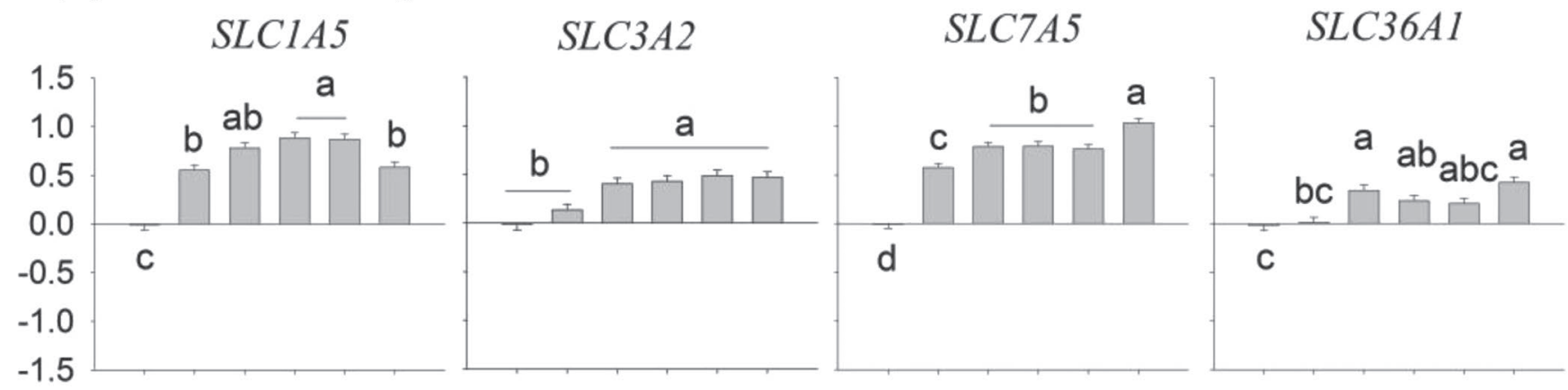

(B) Glucose transporters

(C) JAK2-STAT5 signaling
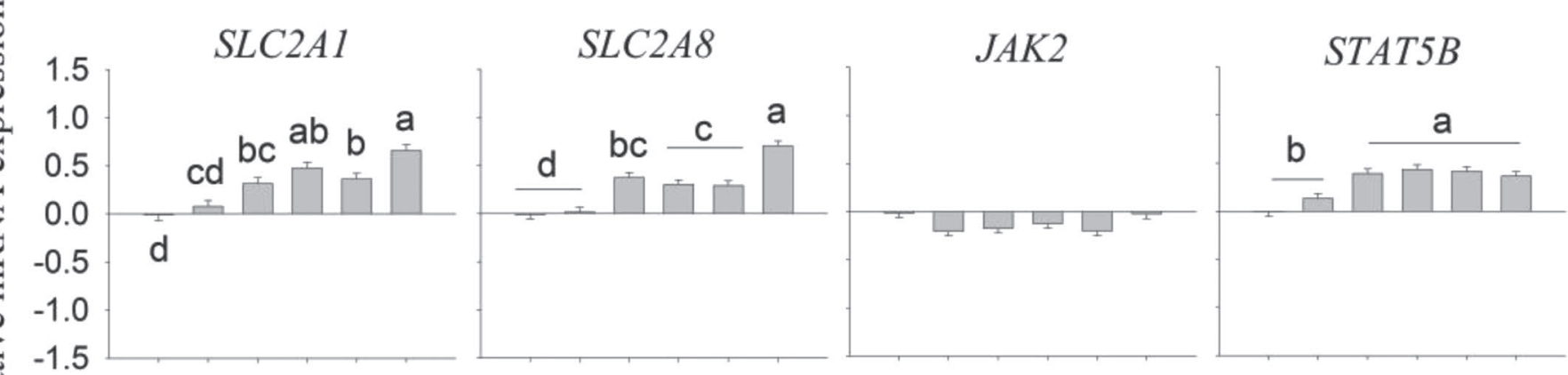

(D) Insulin signaling
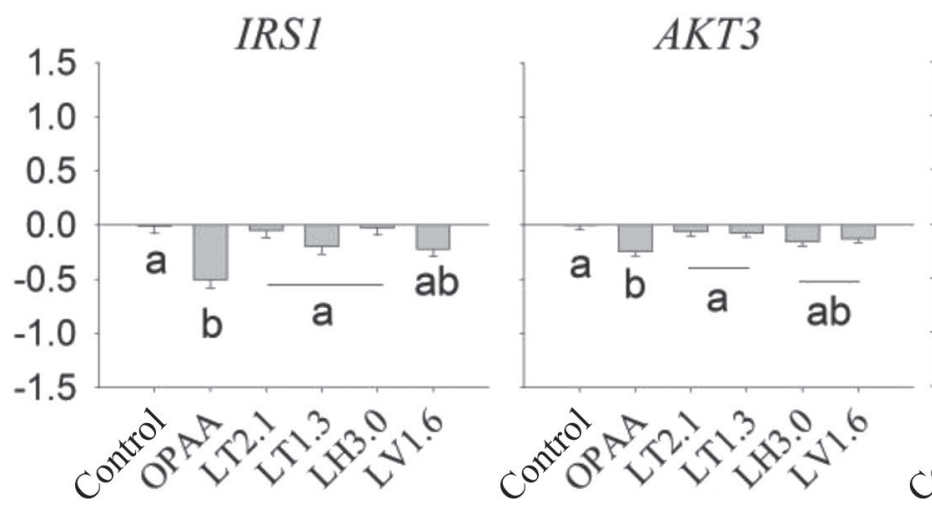

(E) Translation elongation

\section{EEF1A1}

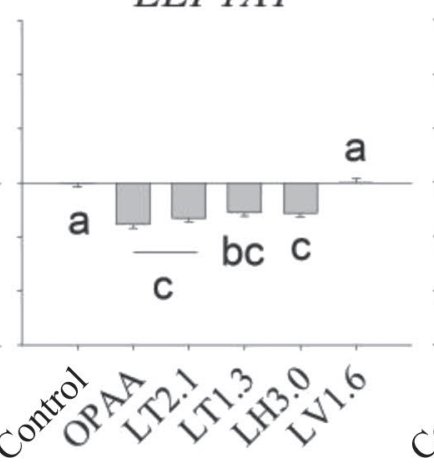

EEF2

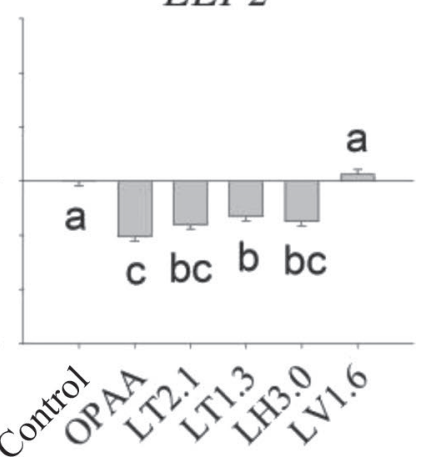

Figure 2. Changes in the mRNA abundance of genes involved in (A) AA transport, (B) glucose transport, (C) JAK2-STAT5 signaling, (D) insulin signaling, and (E) translation elongation in MAC-T cells cultured with various essential AA ratios. The values shown are the means \pm SEM $(\mathrm{n}=3$ per group). Values without a common letter differ $(P<0.05)$. Control $=$ optimal AA with rapamycin; OPAA $=$ optimal AA; LT2.1 = Lys:Thr ratio of 2.1; LT1.3 = Lys:Thr ratio of 1.3; LH3.0 = Lys:His ratio of 3.05; LV1.6 = Lys:Val ratio of 1.62. AKT3 = v-akt murine thymoma viral oncogene homolog $3 ; E E F 1 A 1=$ eukaryotic translation elongation factor $1 \alpha 1 ; E E F 2=$ eukaryotic translation elongation factor 2; IRS1 = insulin receptor substrate 1; JAK2 = Janus kinase 2 (a protein tyrosine kinase); SLC1A5= solute carrier family 1 (neutral AA transporter) member 5; SLC2A1 = solute carrier family 2 (facilitated glucose transporter) member 1; SLC2A8= solute carrier family 2 (facilitated glucose transporter) member $8 ; S L C 3 A 2=$ solute carrier family 3 (activators of dibasic and neutral AA transporter) member 2; SLC7A5 = solute carrier family 7 (cationic AA transporter, y+ system) member 5; SLC36A1 = solute carrier family 36 (proton/AA symporter) member 1; STAT5B = signal transducer and activator of transcription $5 \mathrm{~A}$.

al., 2012a,b). A balanced ratio of the EAA reaching the small intestine plays a critical role in milk protein synthesis (Haque et al., 2012, 2015). Besides Lys and Met, other AA such as Thr, His, and Val are also recognized to be essential for the synthesis of milk protein (Prizant and Barash, 2008; Lee et al., 2012; Haque et al., 2013). In murine and bovine mammary cells, Thr inhibited S6K1 phosphorylation via the specific AA pathway that directs signals to mTOR (Prizant and Barash, 2008). Increasing the postruminal supply of His increased the milk protein yield in dairy cows receiving an MP-deficient diet (Lee et al., 2012). Addition of His 
(A) mTOR signaling

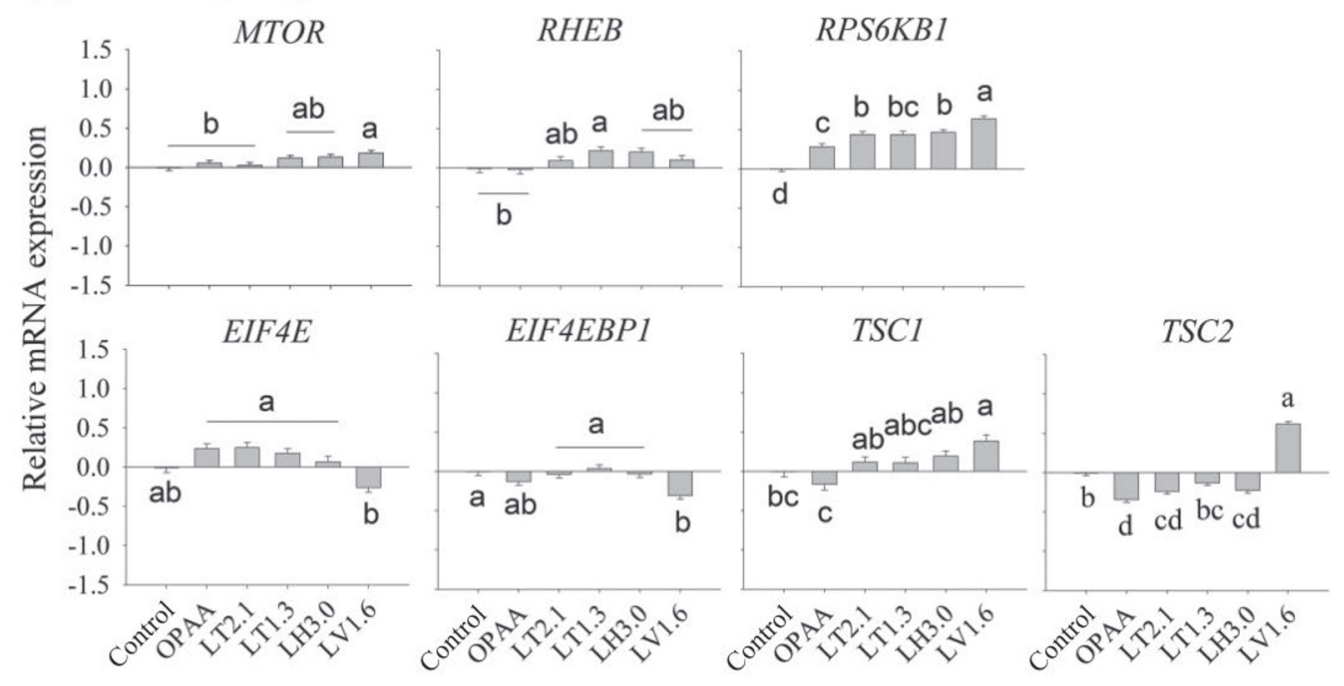

(B)

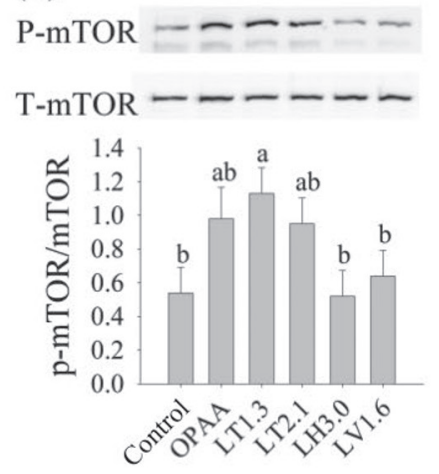

(E)
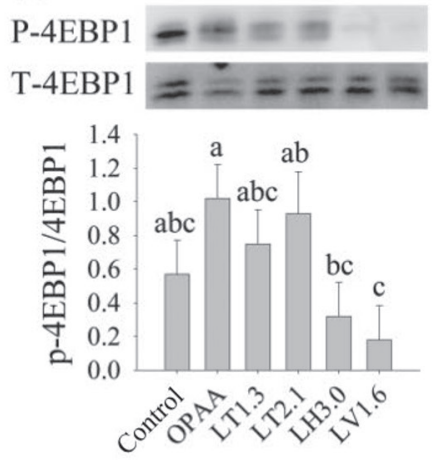

(C)
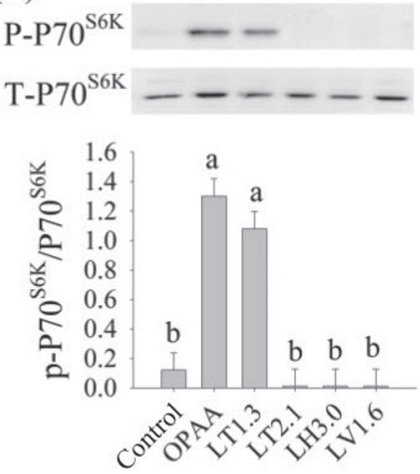

(F)
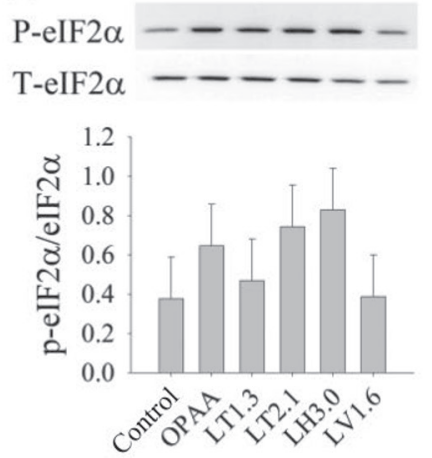

(D)

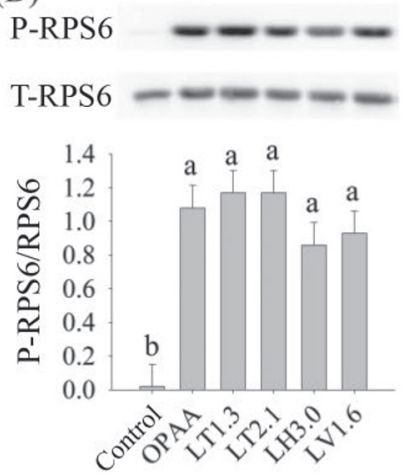

(G)
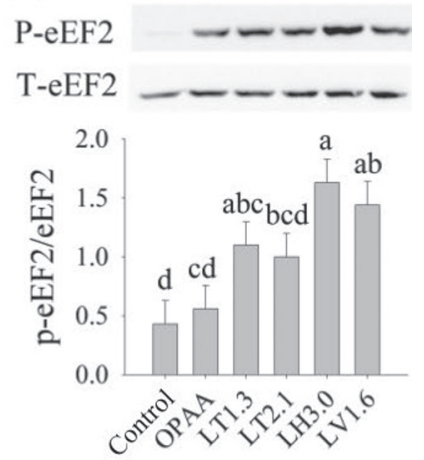

Figure 3. (A) Relative mRNA expression. Protein abundance of the phosphorylation state (B) mTOR, (C) P70 ${ }^{\mathrm{S} 6 \mathrm{~K}}$, (D) RPS6, (E) 4EBP1, (F) eIF2 $\alpha$, and (G) eEF2 in MAC-T cells cultured with the various AA ratios. The values are the means \pm SEM ( $\mathrm{n}=3$ per group). Values without a common letter $\operatorname{differ}(P<0.05)$. Control = optimal AA with rapamycin; OPAA = optimal AA; LT2.1 = Lys:Thr ratio of 2.1 ; LT1.3 $=$ Lys:Thr ratio of 1.3; LH3.0 = Lys:His ratio of 3.05; LV1.6 = Lys:Val ratio of 1.62. EIF $4 E=$ eukaryotic translation initiation factor $4 \mathrm{E}$; $E I F 4 E B P 1=$ eukaryotic translation initiation factor $4 \mathrm{E}$ binding protein 1; $M T O R=$ mammalian target of rapamycin; $R H E B=$ Ras homolog enriched in brain; RPS6KB1 = ribosomal protein S6 kinase $\beta-1 ; T S C 1=$ tuberous sclerosis $1 ;$ TSC2 = tuberous sclerosis 2 ; p-mTOR $=$ phosphorylated mammalian target of rapamycin; $\mathrm{P} 70^{\mathrm{S} 6 \mathrm{~K}}=$ ribosomal protein $\mathrm{S} 6$ kinase; p-P70 $0^{\mathrm{S} 6 \mathrm{~K}}=$ phosphorylated ribosomal protein $\mathrm{S} 6$ kinase; RPS6 = ribosomal protein S6; p-RPS6 = phosphorylated ribosomal protein S6; 4EBP1 = eukaryotic translation initiation factor 4E binding protein $1 ; \mathrm{p}-4 \mathrm{EBP} 1=$ phosphorylated eukaryotic translation initiation factor $4 \mathrm{E}$ binding protein 1 ; eIF $2 \alpha=\alpha$ subunit of eukaryotic translation initiation factor 2 ; p-eIF $2 \alpha=$ phosphorylated $\alpha$ subunit of eukaryotic translation initiation factor 2; eEF2 = eukaryotic translation elongation factor 2 ; p-eEF2 = phosphorylated eukaryotic translation elongation factor $2 . \mathrm{P}=$ phosphorylated; $\mathrm{T}=$ total. 


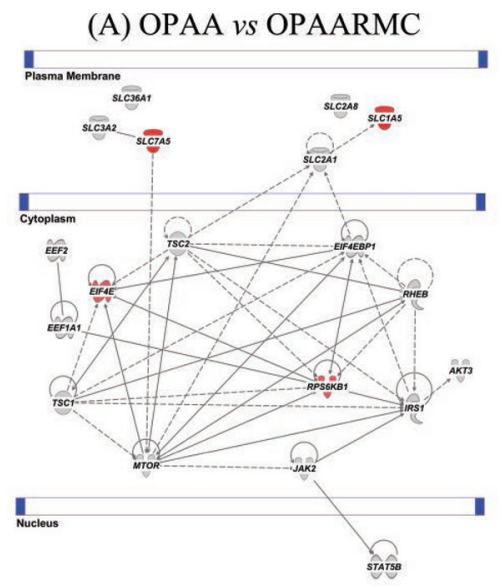

(C) LT1.3 vs OPAARMC

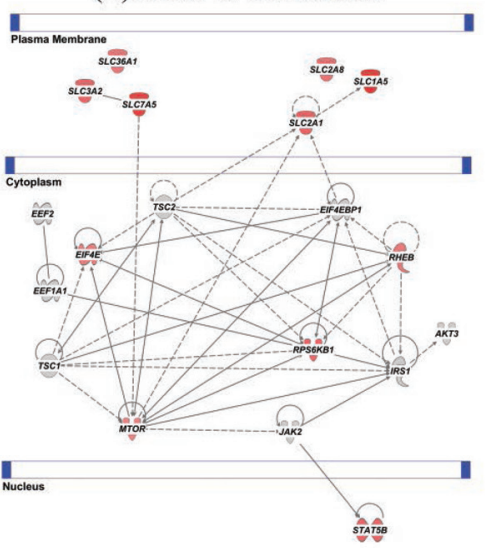

(E) LV1.6 vs OPAARMC

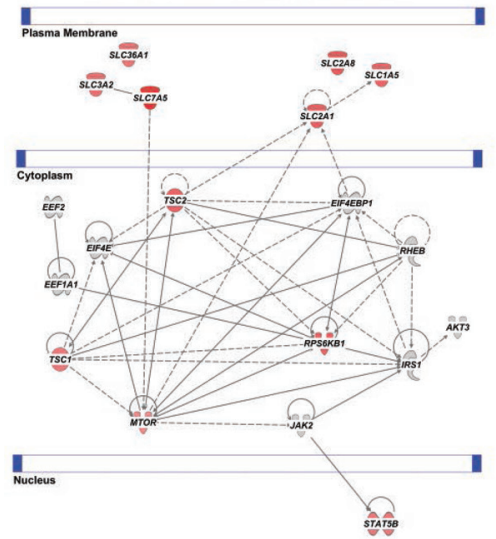

(B) LT2.1 vs OPAARMC

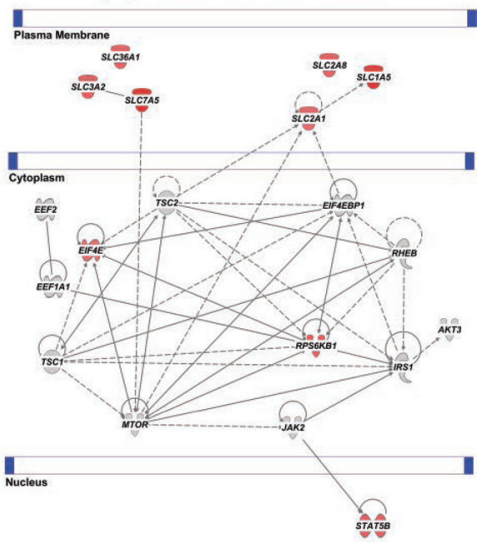

(D) LH3.0 vs OPAARMC

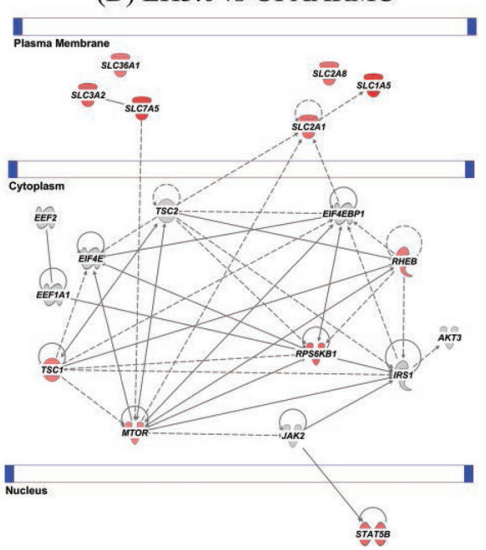

Figure 4. Summary of the potential regulatory network of genes associated with milk protein in response to various AA ratios in MAC-T cells. The networks were developed using Ingenuity Pathway Analysis software (Ingenuity Systems, Redwood City, CA; www.ingenuity.com). Genes with a red background were upregulated by the specific treatment, and those with a gray background were not affected by treatments. Arrows with solid and dotted lines indicate direct and indirect interactions among genes, respectively. Control = optimal AA with rapamycin; OPAA = optimal AA; LT2.1 = Lys:Thr ratio of 2.1; LT1.3 = Lys:Thr ratio of 1.3; LH3.0 = Lys:His ratio of 3.05 ; LV1.6 = Lys:Val ratio of 1.62. $A K T 3=$ v-akt murine thymoma viral oncogene homolog $3 ; E E F 1 A 1=$ eukaryotic translation elongation factor $1 \propto 1 ; E E F 2=$ eukaryotic translation elongation factor $2 ; E I F 4 E=$ eukaryotic translation initiation factor $4 \mathrm{E} ; E I F 4 E B P 1=$ eukaryotic translation initiation factor $4 \mathrm{E}$ binding protein 1; IRS1 = insulin receptor substrate 1; JAK2 = Janus kinase 2 (a protein tyrosine kinase); $M T O R=$ mammalian target of rapamycin; $R H E B=$ Ras homolog enriched in brain; $R P S 6 K B 1=$ ribosomal protein S6 kinase $\beta-1 ; S L C 1 A 5=$ solute carrier family 1 (neutral AA transporter) member 5; SLC2A1 = solute carrier family 2 (facilitated glucose transporter) member 1:SLC2A8= solute carrier family 2 (facilitated glucose transporter) member $8 ; S L C 3 A 2=$ solute carrier family 3 (activators of dibasic and neutral AA transporter) member 2 ; $S L C 7 A 5=$ solute carrier family 7 (cationic AA transporter, y+ system) member $5 ; S L C 36 A 1=$ solute carrier family 36 (proton/AA symporter) member 1; STAT5B = signal transducer and activator of transcription $5 \mathrm{~A}$; TSC1 = tuberous sclerosis 1 ; TSC2 = tuberous sclerosis 2 . Color version available online. 
also had a negative effect on S6K1 phosphorylation in mammary cells (Prizant and Barash, 2008). A decrease in the supply of Val can limit milk protein synthesis (Schwab et al., 1976; Haque et al., 2013). Our previous data demonstrated that an optimal ratio of Lys to Met or Thr to Phe increased milk yield and milk protein content in dairy cows (Wang et al., 2010) or in bovine MEC (Zhou et al., 2015). In this study, we confirmed that the OPAA could stimulate the synthesis of $\beta-C N$ in bovine MTE. Use of bovine MTE for incubations with the various EAA ratios allowed for evaluating the effect on $\beta$-CN expression because of the difficulty in detecting this protein in MAC-T cells (Appuhamy et al., 2011, 2012). Further studies in both bovine primary MEC and MTE are needed to explore the effect of the ratio of EAA on milk protein synthesis and the underlying mechanisms.

The absorbed AA, which are assimilated and metabolized by body tissues, require membrane-spanning transporters to help translocate them across the cell membranes (Poncet and Taylor, 2013). Generally, the AA transporters can accept a range of structurally similar AA, such that multiple transporters may medi-

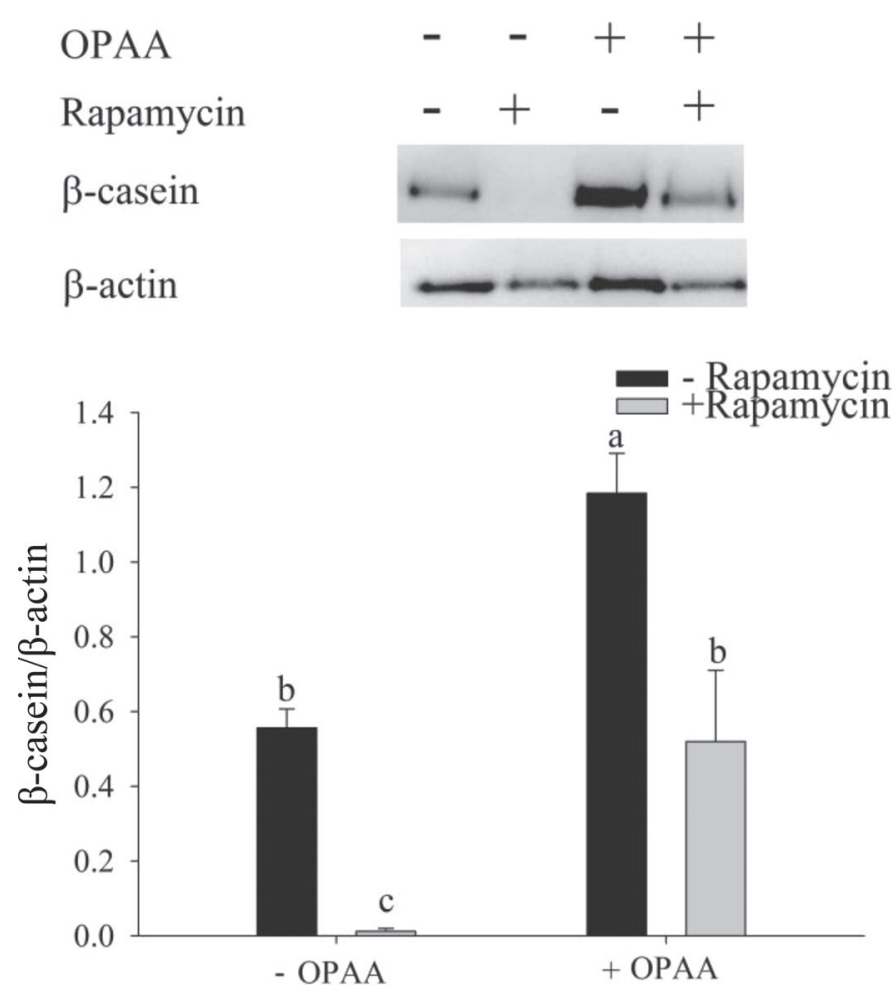

Figure 5. Relative protein expression of $\beta-\mathrm{CN}$ in bovine mammary explants cultured with or without optimal AA and rapamycin. The values are the means \pm SEM ( $\mathrm{n}=3$ per group). Values without a common letter differ $(P<0.05)$. - OPAA $=$ high-glucose Dulbecco's modified Eagle's medium without optimal AA; + OPAA = optimal AA. ate the transport of a given AA across a particular cell membrane (Poncet and Taylor, 2013). In the present study, we measured 4 mTOR-mediated AA transporters, including 2 that actively pump AA into mammary cells (SLC1A5 and SLC36A1) and 2 antiporters of cationic AA (SLC3A2 and SLC7A5; Baumrucker, 1985; Fuchs and Bode, 2005; Nicklin et al., 2009).

The upregulation of SLC1A5 and SLC7A5 by OPAA indicated that they may be under the control of mTOR (Bionaz and Loor, 2011). The genes SLC1A5 and SLC7A5 encode the AA transporter systems ASC and L, which are responsible for the exchange of neutral AA, including Thr, Phe, Met, His, Val, and Leu, across the apical membrane (Kadegowda et al., 2009; Lee et al., 2012). Using bovine mammary gland biopsies during the lactation cycle, Bionaz and Loor (2011) demonstrated a similar time-dependent pattern of increases in the expression of SLC1A5 and SLC7A5. Compared with OPAA, the increases in the expression of SLC3A2 and $S L C 7 A 5$ in response to LT2.1, LH3.0, and LV1.6 might indicate that Thr, His, and Val are actively imported into the cells. Another reason may be attributed to the positive effect on Thr, His, and Val through the active transport of Leu (Appuhamy et al., 2012). Further research is needed to verify these functions through the use of protein expression of the 2 AA transporters.

The reciprocal regulatory connection of the functional heterodimer AA transporter (SLC7A5-SLC3A2) and $S L C 1 A 5$ with mTOR may explain the greater expression of SLC1A5, SLC3A2, and SLC7A5 in response to LT1.3 (Fuchs and Bode, 2005). The increase in expression of $S L C 36 A 1$ with LT2.1 and LV1.6 indicated a role of SLC36A1 in the regulation or buffering of mTOR signaling through modulating the availability of AA such as Thr and Val inside the cell (Heublein et al., 2010).

Previous research has demonstrated a potential functional link among the expression of glucose transporters (SLC2A1 and SLC2A8) with mTOR and phosphatidylinositide 3-kinase-linked signaling (Bionaz and Loor, 2011; Zhao et al., 2014). Furthermore, the increased expression of SLC2A1 and SLC2A8 during lactation indicates a critical role in milk protein secretion (Bionaz and Loor, 2011; Zhao, 2014). The greater expression of SLC2A1 and SLC2A8 in LT1.3, LH3.0, and LV1.6 indicated that Thr, His, and Val might promote glucose uptake into the cells under the control of mTOR and potentially be a part of a cross-talk with insulin signaling at the transcriptional level (Buller et al., 2008). Collectively, these results indicate that the stimulating effect of OPAA on the $\beta$-CN synthesis in bovine MEC might be at least partly controlled by enhancing AA uptake (i.e., SLC1A5 and SLC7A5). The molecular 

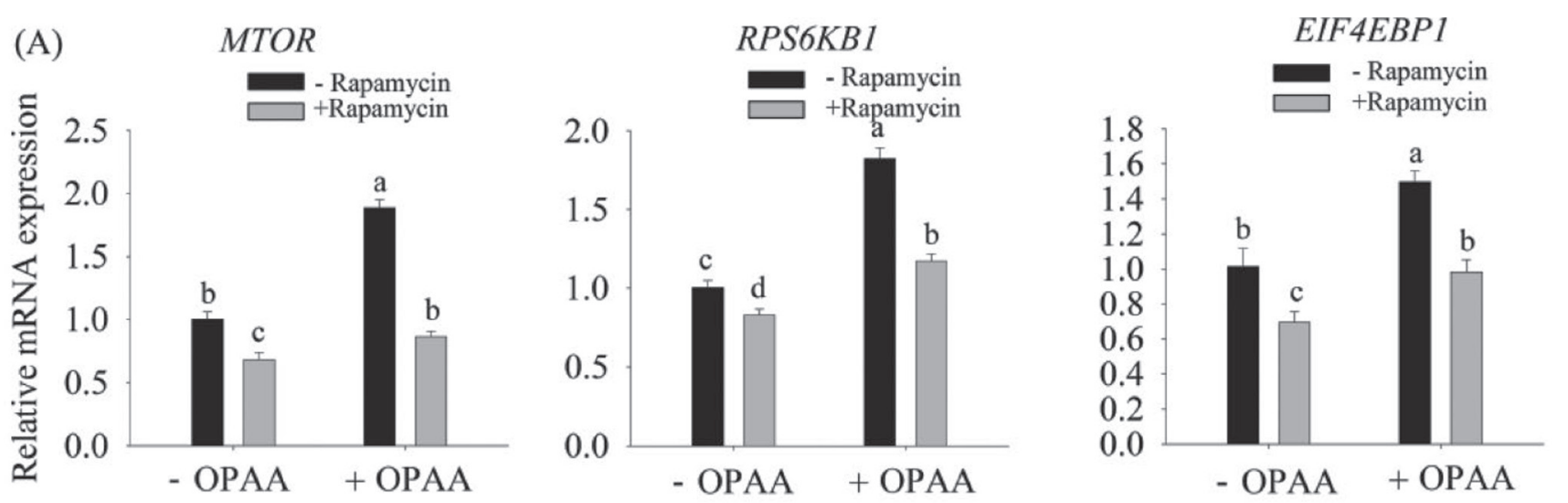

(B)
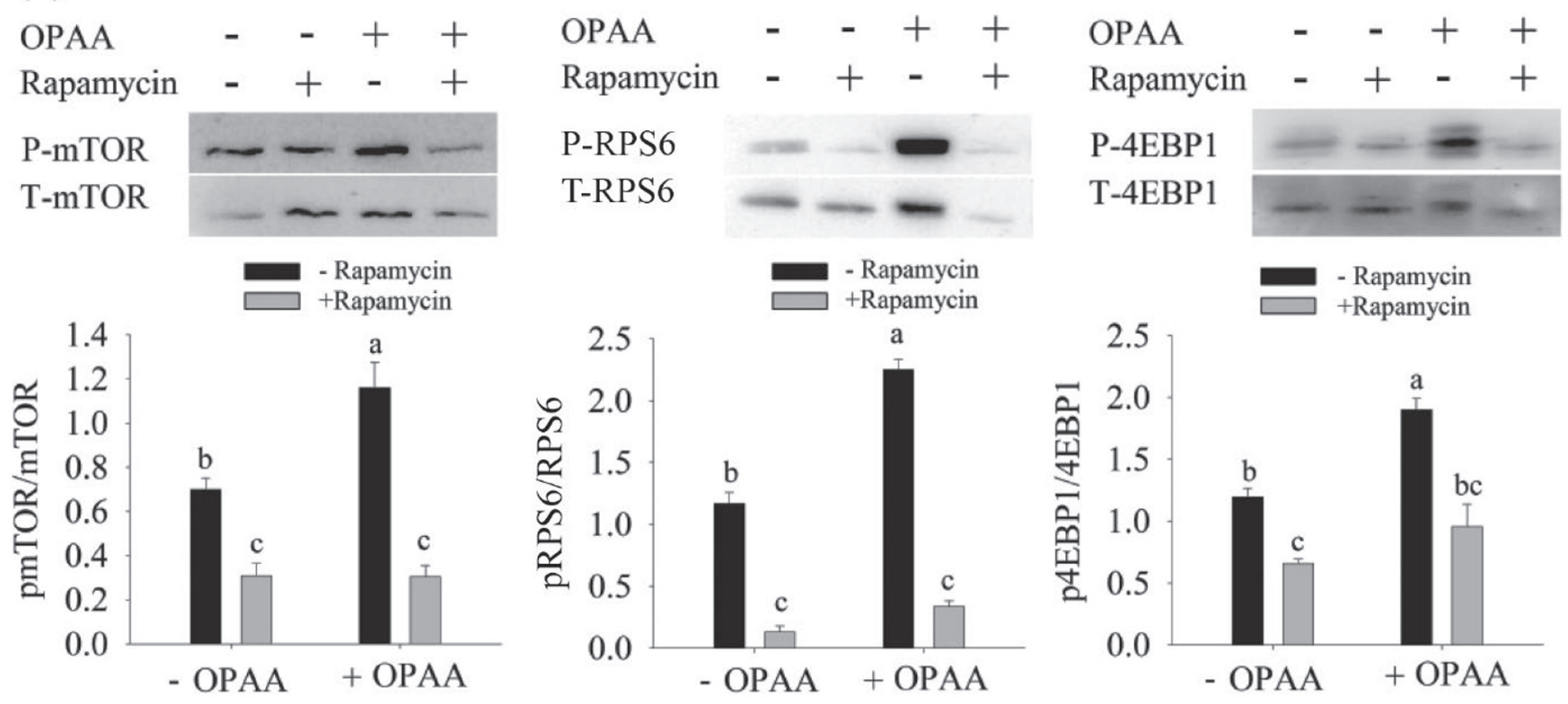

(C)
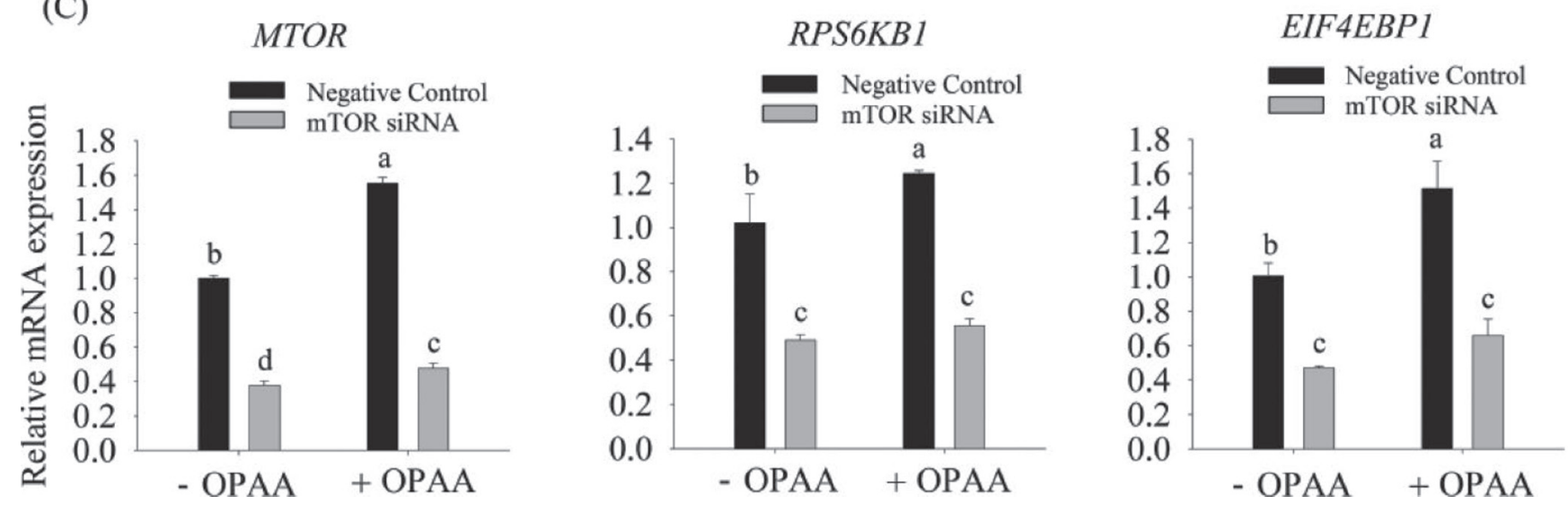

Figure 6. Effect of mammalian target of rapamycin (mTOR) inhibition on the expression of mTOR, S6K1, and 4EBP1 in MAC-T cells cultured with or without optimal AA (OPAA). The relative mRNA expression of (A) MTOR, RPS6KB1, and EIF4EBP1 and (B) phosphorylated (p) mTOR, RPS6, and 4EBP1 in MAC-T cells cultured with or without OPAA and rapamycin. (C) The relative mRNA expression of $M T O R$, RPS6KB1, and EIF4EBP1 in MAC-T cells cultured with or without OPAA and mTOR-specific small interference (si) RNA. The values shown are the means \pm SEM ( $\mathrm{n}=3$ per group). Values without a common letter differ $(P<0.05)$. - OPAA = high-glucose Dulbecco's modified Eagle's medium without optimal AA; + OPAA = optimal AA. MTOR = mammalian target of rapamycin; RPS6KB1 = ribosomal protein S6 kinase $\beta-1 ; \mathrm{RPS} 6=$ ribosomal protein $\mathrm{S} 6 ; 4 \mathrm{EBP} 1=$ eukaryotic translation initiation factor $4 \mathrm{E}$ binding protein $1 . \mathrm{P}=$ phosphorylated; $\mathrm{T}=$ total. 
mechanisms that link AA transport and intracellular trafficking in MEC as a means of regulating milk protein synthesis remain to be investigated.

Previous data from murine MEC indicated that the JAK2-STAT2 signaling pathway could mediate the induction of $\beta$-CN transcription via prolactin and growth hormone (Buser et al., 2007). Prolactin and growth hormone activate and phosphorylate JAK2 upon binding to their receptors. Thereafter, STAT5 is phosphorylated by JAK2 to form dimers that translocate to the nucleus, where they influence $\beta-\mathrm{CN}$ gene transcription (Buser et al., 2007; Chia, 2014). A previous study reported that a 3:1 Lys:Met ratio and Met-Met could increase the $\alpha_{\mathrm{S} 1}-\mathrm{CN}$ mRNA abundance in bovine MEC or MTE (Nan et al., 2014; Yang et al., 2015). In the present study, the marked upregulation of STAT5B detected following treatment with LT2.1, LH3.0, and LV1.6 might have played a role in the stimulation of $\beta$-CN mRNA expression. The downregulation of IRS1 and AKT3 by OPAA compared with the control indicated that mTOR might reduce the insulin sensitivity in MEC through the IRS1-phosphoinositol dependent kinase (PDK)-protein kinase B (AKT) signaling pathway (Arriola Apelo et al., 2014). Another possibility is that hyperactivation of the mTOR pathway exerted a negative feedback on the insulin signals via IRS1 phosphorylation in MAC-T cells (Appuhamy et al., 2011), indicating a compensatory reduction in the transcription of these genes when mTOR is activated.

The phosphorylation of mTOR at Ser2448 activates the pathway (Dibble and Manning, 2013). Although treatment with OPAA had no effect on phosphorylation state of mTOR, the phosphorylation of S6K1 and RPS6 was enhanced compared with the control. Similar results were also detected at the transcription level. Compared with OPAA, an unbalanced ratio of Lys to Thr, His, and Val (LT2.1, LH3.0, and LV1.6) resulted in the inactivation of S6K1, which might have been due to their negative influence through the TSC1/TSC2 complex on mTOR signaling. Among the inhibitors of mTOR signaling, the TSC complex is sensitive to insulin signaling, which in turn inhibits mTOR via RHEB (Bionaz and Loor, 2011). In the present work, the increased expression of TSC1 mRNA following treatment with LT2.1, LH3.0, and LV1.6 and of TSC2 following treatment with LT1.3 and LV1.6 might have attenuated the mTOR signaling via $R H E B$ at the transcriptional level.

When the cells were treated with rapamycin (an inhibitor of mTOR), the stimulatory effect of OPAA on the synthesis of $\beta-\mathrm{CN}$ (as well as abundance of phosphorylated RPS6 and 4EBP1 protein) was markedly decreased. Considering that rapamycin may not inhibit all of the mTOR functions (Rosario et al., 2013), the silencing of mTOR could permit elucidation of the essential components of the mTOR signaling pathway. In particular, the similar effect of rapamycin and the silencing of mTOR on the expression of RPS6KB1 and EIF $4 E B P 1$ mRNA underscore that the OPAA-induced stimulation of $\beta-\mathrm{CN}$ synthesis is mediated through the mTOR-S6K1-4EBP1 signaling pathway.

The eIF2 $\alpha$ factor is critical for the initiation of protein translation (Proud, 2007). Deficiencies in AA and other cellular stresses have been associated with an increase in eIF $2 \alpha$ phosphorylation, which results in an inhibition of mRNA translation through integrated stressresponse networks (Toerien et al., 2010). Furthermore, the phosphorylation of eIF $2 \alpha$ is negatively correlated with milk protein synthesis rates (Appuhamy et al., 2012). The lack of an effect of any of the treatments on eIF $2 \alpha$ in the present study indicated that it cannot be activated when AA availability is sufficient. Furthermore, the nonsignificant difference between OPAA and the control (in the presence of rapamycin) is consistent with the idea that eIF $2 \alpha$ activity is not under the control of mTOR (Appuhamy et al., 2011).

The phosphoprotein eEF2 can mediate the elongation step during translation (Kaul et al., 2011). Similar to eIF $2 \alpha$, it also had a negative association with fractional rates of protein synthesis in bovine mammary tissue slices (Appuhamy et al., 2011, 2012). In the present study, the increase in the expression of eEF2 mRNA and the phosphorylation of this protein when the cells were cultured with LV1.6 compared with OPAA was somewhat indicative of a lower expression of $\beta$-CN. Furthermore, although LH3.0 increased the phosphorylation of eEF2 and LT1.3 increased the mRNA expression of eEF2, no differences were detected at the transcriptional or translational levels. The differences in the regulation may be attributable to different translation efficiencies and posttranscriptional modifications of the same gene - for example, effects due to the GC content, secondary structure, $5^{\prime}$ and $3^{\prime}$ untranslated regions, codon usage efficiencies, and protein binding sites that influence ribosome recruitment and transit (Kim et al., 2015). In addition, the downregulation of EEF2 following the OPAA treatment compared with the control indicated that eEF2 could be modulated by AA in an mTOR-dependent manner (Appuhamy et al., 2012). The data from the present study indicated that the positive effect of OPAA could be mediated by negative regulation of the translation elongation step, especially by eEF2.

\section{CONCLUSIONS}

Optimal EAA ratios stimulated the $\beta-\mathrm{CN}$ expression in bovine mammary gland explants. Network visualiza- 
tion indicated that an increase in milk protein synthesis may be driven by the transport of AA into the cells, cross-talk with insulin signaling, and enhancement of mTOR signaling or translation elongation. These systematic findings provide additional information regarding the global molecular mechanisms that control milk protein synthesis. Thus, in the long term, they could serve as targets for improving the efficiency of utilization of dietary nitrogen in dairy cows.

\section{ACKNOWLEDGMENTS}

This research was partly supported by grants from the China Agriculture (Dairy) Research System (CARS-37, Beijing, China), the National Institute of Food and Agriculture (Washington, DC; ILLU-538-914), and the China Postdoctoral Science Foundation (2015M581949, Beijing, China). The authors thank the Jiashan Dayang Animal Slaughter House (Jiaxing, China) for providing the bovine mammary tissue.

\section{REFERENCES}

Appuhamy, J. A., A. L. Bell, W. A. Nayananjalie, J. Escobar, and M. D. Hanigan. 2011. Essential amino acids regulate both initiation and elongation of mRNA translation independent of insulin in MAC-T cells and bovine mammary tissue slices. J. Nutr. 141:1209-1215.

Appuhamy, J. A., N. A. Knoebel, W. A. Nayananjalie, J. Escobar, and M. D. Hanigan. 2012. Isoleucine and leucine independently regulate mTOR signaling and protein synthesis in MAC-T cells and bovine mammary tissue slices. J. Nutr. 142:484-491.

Areta, J. L., J. A. Hawley, J. M. Ye, M. H. Chan, and V. G. Coffey. 2014. Increasing leucine concentration stimulates mechanistic target of rapamycin signaling and cell growth in $\mathrm{C} 2 \mathrm{C} 12$ skeletal muscle cells. Nutr. Res. 34:1000-1007.

Arriola Apelo, S. I., J. R. Knapp, and M. D. Hanigan. 2014. Invited review: Current representation and future trends of predicting amino acid utilization in the lactating dairy cow. J. Dairy Sci. 97:4000-4017.

Baumrucker, C. R. 1985. Amino acid transport systems in bovine mammary tissue. J. Dairy Sci. 68:2436-2451.

Bionaz, M., and J. J. Loor. 2011. Gene networks driving bovine mammary protein synthesis during the lactation cycle. Bioinform. Biol. Insights 5:83-98.

Buller, C. L., R. D. Loberg, M. H. Fan, Q. Zhu, J. L. Park, E. Vesely, K. Inoki, K. L. Guan, and F. C. Brosius III.. 2008. A GSK-3/ TSC2/mTOR pathway regulates glucose uptake and GLUT1 glucose transporter expression. Am. J. Physiol. Cell Physiol. 295:C836-C843.

Buser, A. C., E. K. Gass-Handel, S. L. Wyszomierski, W. Doppler, S. A. Leonhardt, J. Schaack, J. M. Rosen, H. Watkin, S. M. Anderson, and D. P. Edwards. 2007. Progesterone receptor repression of prolactin/signal transducer and activator of transcription 5-mediated transcription of the beta-casein gene in mammary epithelial cells. Mol. Endocrinol. 21:106-125.

Chia, D. J. 2014. Minireview: Mechanisms of growth hormone-mediated gene regulation. Mol. Endocrinol. 28:1012-1025.

Clark, R. M., P. T. Chandler, and C. S. Park. 1978. Limiting amino acids for milk protein synthesis by bovine mammary cells in culture. J. Dairy Sci. 61:408-413.

Dibble, C. C., and B. D. Manning. 2013. Signal integration by mTORC1 coordinates nutrient input with biosynthetic output. Nat. Cell Biol. 15:555-564.
Fuchs, B. C., and B. P. Bode. 2005. Amino acid transporters ASCT2 and LAT1 in cancer: Partners in crime? Semin. Cancer Biol. $15: 254-266$.

Gao, H. N., H. Hu, N. Zheng, and J. Q. Wang. 2015. Leucine and histidine independently regulate milk protein synthesis in bovine mammary epithelial cells via mTOR signaling pathway. J. Zhejiang Univ. Sci. B 16:560-572.

Haque, M. N., J. Guinard-Flament, P. Lamberton, C. Mustiere, and S. Lemosquet. 2015. Changes in mammary metabolism in response to the provision of an ideal amino acid profile at 2 levels of metabolizable protein supply in dairy cows: Consequences on efficiency. J. Dairy Sci. 98:3951-3968.

Haque, M. N., H. Rulquin, A. Andrade, P. Faverdin, J. L. Peyraud, and S. Lemosquet. 2012. Milk protein synthesis in response to the provision of an "ideal" amino acid profile at 2 levels of metabolizable protein supply in dairy cows. J. Dairy Sci. 95:5876-5887.

Haque, M. N., H. Rulquin, and S. Lemosquet. 2013. Milk protein responses in dairy cows to changes in postruminal supplies of arginine, isoleucine, and valine. J. Dairy Sci. 96:420-430.

Heublein, S., S. Kazi, M. H. Ogmundsdottir, E. V. Attwood, S. Kala, C. A. Boyd, C. Wilson, and D. C. Goberdhan. 2010. Proton-assisted amino-acid transporters are conserved regulators of proliferation and amino-acid-dependent mTORC1 activation. Oncogene 29:4068-4079.

Jewell, J. L., R. C. Russell, and K. L. Guan. 2013. Amino acid signaling upstream of mTOR. Nat. Rev. Mol. Cell Biol. 14:133-139.

Kadegowda, A. K., M. Bionaz, L. S. Piperova, R. A. Erdman, and J. J. Loor. 2009. Peroxisome proliferator-activated receptor-gamma activation and long-chain fatty acids alter lipogenic gene networks in bovine mammary epithelial cells to various extents. J. Dairy Sci. 92:4276-4289.

Kaul, G., G. Pattan, and T. Rafeequi. 2011. Eukaryotic elongation factor-2 (eEF2): Its regulation and peptide chain elongation. Cell Biochem. Funct. 29:227-234.

Kim, J. J., J. Yu, J. Bag, M. Bakovic, and J. P. Cant. 2015. Translation attenuation via $3^{\prime}$ terminal codon usage in bovine csn1s2 is responsible for the difference in $\alpha_{\mathrm{s} 2^{-}}$and $\beta$-casein profile in milk. RNA Biol. 12:354-367.

Kim, S. G., G. R. Buel, and J. Blenis. 2013. Nutrient regulation of the mTOR complex 1 signaling pathway. Mol. Cells 35:463-473.

Lee, C., A. N. Hristov, T. W. Cassidy, K. S. Heyler, H. Lapierre, G. A. Varga, M. J. de Veth, R. A. Patton, and C. Parys. 2012. Rumenprotected lysine, methionine, and histidine increase milk protein yield in dairy cows fed a metabolizable protein-deficient diet. J. Dairy Sci. 95:6042-6056.

Li, S., A. Hosseini, M. Danes, C. Jacometo, J. X. Liu, and J. J. Loor. 2016. Essential amino acid ratios and mTOR affect lipogenic gene networks and miRNA expression in bovine mammary epithelial cells. J. Anim. Sci. Biotechnol. 7:44.

Li, S. S., J. S. Shen, D. X. Ren, and J. X. Liu. 2015. Effects of the processing methods of corn grain and soybean meal on milk protein expression profiles in dairy cows. Animal 9:267-274.

Lu, L. M., X. J. Gao, Q. Z. Li, J. G. Huang, R. Liu, and H. M. Li. 2012a. Comparative phosphoproteomics analysis of the effects of L-methionine on dairy cow mammary epithelial cells. Can. J. Anim. Sci. 92:433-442.

Lu, L. M., Q. Z. Li, J. G. Huang, and X. J. Gao. 2012b. Proteomic and functional analyses reveal MAPK1 regulates milk protein synthesis. Molecules 18:263-275.

Moshel, Y., R. E. Rhoads, and I. Barash. 2006. Role of amino acids in translational mechanisms governing milk protein synthesis in murine and ruminant mammary epithelial cells. J. Cell. Biochem. 98:685-700.

Nan, X., D. Bu, X. Li, J. Wang, H. Wei, H. Hu, L. Zhou, and J. J. Loor. 2014. Ratio of lysine to methionine alters expression of genes involved in milk protein transcription and translation and mTOR phosphorylation in bovine mammary cells. Physiol. Genomics 46:268-275.

National Research Council. 2001. Nutrient Requirements of Dairy Cattle. 7th rev. ed. Natl. Acad. Press, Washington, DC. 
Nicklin, P., P. Bergman, B. Zhang, E. Triantafellow, H. Wang, B. Nyfeler, H. Yang, M. Hild, C. Kung, C. Wilson, V. E. Myer, J. P. MacKeigan, J. A. Porter, Y. K. Wang, L. C. Cantley, P. M. Finan, and L. O. Murphy. 2009. Bidirectional transport of amino acids regulates mTOR and autophagy. Cell 136:521-534.

Poncet, N., and P. M. Taylor. 2013. The role of amino acid transporters in nutrition. Curr. Opin. Clin. Nutr. Metab. Care 16:57-65.

Prizant, R. L., and I. Barash. 2008. Negative effects of the amino acids Lys, His, and Thr on S6K1 phosphorylation in mammary epithelial cells. J. Cell. Biochem. 105:1038-1047.

Proud, C. G. 2007. Signaling to translation: How signal transduction pathways control the protein synthetic machinery. Biochem. J. 403:217-234

Rosario, F. J., Y. Kanai, T. L. Powell, and T. Jansson. 2013. Mammalian target of rapamycin signaling modulates amino acid uptake by regulating transporter cell surface abundance in primary human trophoblast cells. J. Physiol. 591:609-625.

Rulquin, H., G. Raggio, H. Lapierre, and S. Lemosquet. 2007. Relationship between intestinal supply of essential amino acids and their mammary metabolism in the lactating dairy cow. Pages 587588 in Energy and Protein Metabolism and Nutrition. I. OrtiguesMarty, N. Miraux, and W. Brand-Williams, ed. Wageningen Academic Publishers, Wageningen, the Netherlands.

Schwab, C. G., L. D. Satter, and B. Clay. 1976. Response to lactating dairy cows to abomasal infusion of amino acids. J. Dairy Sci. 59:1254-1270.

Shimobayashi, M., and M. N. Hall. 2014. Making new contacts: The mTOR network in metabolism and signaling crosstalk. Nat. Rev. Mol. Cell Biol. 15:155-162.
Toerien, C. A., D. R. Trout, and J. P. Cant. 2010. Nutritional stimulation of milk protein yield of cows is associated with changes in phosphorylation of mammary eukaryotic initiation factor 2 and ribosomal S6 kinase 1. J. Nutr. 140:285-292.

Wang, C., H. Y. Liu, Y. M. Wang, Z. Q. Yang, J. X. Liu, Y. M. Wu, T. Yan, and H. W. Ye. 2010. Effects of dietary supplementation of methionine and lysine on milk production and nitrogen utilization in dairy cows. J. Dairy Sci. 93:3661-3670.

Wang, M., B. Xu, H. Wang, D. Bu, J. Wang, and J. J. Loor. 2014. Effects of arginine concentration on the in vitro expression of casein and mTOR pathway related genes in mammary epithelial cells from dairy cattle. PLoS One 9:e95985.

Yang, J. X., C. H. Wang, Q. B. Xu, F. Q. Zhao, J. X. Liu, and H. Y Liu. 2015. Methionyl-methionine promotes alpha-s1 casein synthesis in bovine mammary gland explants by enhancing intracellular substrate availability and activating JAK2-STAT5 and mTORmediated signaling pathways. J. Nutr. 145:1748-1753.

Zhao, F. Q. 2014. Biology of glucose transport in the mammary gland. J. Mammary Gland Biol. Neoplasia 19:3-17.

Zhao, K., H. Y. Liu, M. M. Zhou, F. Q. Zhao, and J. X. Liu. 2014 Insulin stimulates glucose uptake via a phosphatidylinositide 3-kinase-linked signaling pathway in bovine mammary epithelial cells. J. Dairy Sci. 97:3660-3665.

Zhou, M. M., Y. M. Wu, H. Y. Liu, and J. X. Liu. 2015. Effects of phenylalanine and threonine oligopeptides on milk protein synthesis in cultured bovine mammary epithelial cells. J. Anim. Physiol. Anim. Nutr. (Berl.) 99:215-220. 